\title{
ENSINANDO A METODOLOGIA DA PROBLEMATIZAÇÃO COM O ARCO DE MAGUEREZ A PARTIR DA ESTRATÉGIA WORLD CAFÉ
}

\author{
TEACHING PROBLEMATIZATION METHODOLOGY WITH MAGUEREZ'S ARCH STARTING WITH WORLD CAFÉ
}

ENSEÑANDO LA PROBLEMATIZACIÓN METODOLÓGICA CON EL ARCO DE MAGUEREZ A PARTIR DE LA ESTRATEGIA WORLD CAFÉ

\author{
FRANZONI, Patricia da Graça Rocha1 \\ CRUZ, Romildo Pereira2 ${ }^{2}$ D \\ QUARTIERI, Marli Teresinha ${ }^{3}$
}

\section{RESUMO}

Este artigo propõe-se a investigar as vantagens de ensinar a metodologia da problematização a partir da estratégia World Café com o objetivo de solucionar problemas do cotidiano e contribuir na formação docente. A estratégia foi desenvolvida com alunos do Programa de Pós-Graduação em Ensino de uma Universidade do Rio Grande do Sul. Pode-se inferir que a atividade realizada foi produtiva, fortalecendo os processos de ensino e de aprendizagem. Percebeu-se que os alunos assumiram um papel mais ativo, foram estimulados a buscarem problemas em seu cotidiano e sentiram-se corresponsáveis pela própria aprendizagem das cinco etapas do Arco de Maguerez a partir da estratégia World Café.

Palavras-chave: Ensino. Problematização. Arco de Maguerez. World Café.

\section{ABSTRACT}

This article proposes to investigate the advantages of teaching the problematization methodology starting from the World Café strategy aiming to solve everyday problems and contribute to the teacher's formation. The strategy has been developed by students of a University from Rio Grande do Sul who are postgraduates in Teaching. It may be inferred that the activity performed was productive, strengthening the teaching and learning processes. It was possible to realize the students assumed a more active role, were stimulated to look for problems in their daily lives and felt corresponsable for their own learning of the five stages of Maguerez's Arch starting with the World Café strategy.

Keywords: Teaching. Problematization. Maguerez's Arch. World Café.

\section{RESUMEN}

Este artículo se propone a investigar las ventajas de enseñar la problematización metodológica a partir de la estrategia World Café, con el objetivo de resolver problemas cotidianos y contribuir para la formación del docente. La estrategia fue desarrollada por alumnos de posgrado en Enseñanza de una universidad de Rio Grande do Sul. Se puede inferir que la actividad realizada ha sido productiva, fortaleciendo los procesos de enseñanza y aprendizaje. Fue posible percibir que los alumnos han tomado un papel más activo, han sido estimulados a buscar problemas en su cotidiano y se han sentido corresponsables por su propio aprendizaje de las cinco etapas del Arco de Maguerez y estrategia World Café.

Palabras clave: Enseñanza. Problematización. Arco de Maguerez. World Café.

\footnotetext{
1 Universidade Federal do Rio Grande - FURG - Rio Grande - Rio Grande do Sul - Brasil

2 Universidade do Vale do Taquari - UNIVATES - Lajeado - Rio Grande do Sul - Brasil

3 Universidade do Vale do Taquari - UNIVATES - Lajeado - Rio Grande do Sul - Brasil
} 


\section{INTRODUÇÃO}

Segundo Nóvoa (2009), a educação está passando por um período de incertezas, em que sentimos a necessidade de mudança, mas nem sempre conseguimos definir a direção a ser tomada. Existe um exagero de discursos redundantes e repetitivos com pobreza de práticas. Assim, a busca por mudanças tornou-se um desafio, tendo em vista que "o ensino tem-se limitado a um processo de memorização de vocábulos, sistemas classificatórios e fórmulas em que os estudantes não são capazes de extrair o significado de sua linguagem" (SANTOS, 2007, p. 484).

Dessa forma, as crescentes transformações sociais impõem às instituições escolares um repensar dos processos de ensino e de aprendizagem visando à formação de um cidadão com um novo perfil, onde habilidades como proatividade, cooperação, criticidade, dentre outras, se sobressaem em detrimento a simples memorização e repetição. O que nos faz inferir que essa atual configuração tem como prioridade o desenvolvimento do pensamento do aluno como uma dimensão fundamental da cognição.

Nesse sentido, os professores têm sido cada vez mais estimulados a repensar suas práticas pedagógicas. Para Freire (1980), o professor deve desenvolver uma postura dialógica em suas aulas, promovendo debates em que o aluno possa tomar parte com suas próprias ideias.

Sendo assim, o professor deve atuar como um mediador, promovendo debates, proporcionando momentos de discussão e reflexão em sala de aula, valorizando as experiências dos alunos a partir de várias estratégias de ensino, tornando dessa forma as aulas mais atrativas. Posto isto, explicita-se que este novo paradigma carece de um novo olhar para a maneira como os docentes têm conduzido às atividades de ensino na maioria das nossas instituições.

Masetto (2003, p. 86), ressalta que "as estratégias de ensino são meios que o professor utiliza em aula para facilitar a aprendizagem dos alunos [...]". Para Anastasiou e Alves (2003, p. 75-76), "estratégia de ensino é a arte de aplicar ou explorar meios e condições favoráveis e disponíveis, com vistas à consecução de objetivos específicos". Ademais, as autoras destacam que para os alunos se apropriarem do conhecimento, o professor deve agir como um verdadeiro estrategista, utilizando ferramentas facilitadoras de aprendizagem (ANASTASIOU e ALVES, 2003).

Dessa forma, os professores dispõem de inúmeras metodologias de ensino com potencial para ressignificar a aprendizagem. Segundo Gil (2012, p. 7), indagações como: "Quais as expectativas dos alunos? Em que medida determinado aprendizado poderá ser significativo para eles? Quais as estratégias mais adequadas para facilitar seu aprendizado?" expressam as preocupações dos professores.

Nesse contexto, "o papel predominante do professor deixa de ser o de ensinar e passa a ser o de ajudar o aluno a aprender. Educar deixa de ser a arte de introduzir ideias na cabeça das pessoas, mas de fazer brotar ideias" (WERNER, BOER, 1984, p. 8).

Durante a aprendizagem, é interessante usar múltiplas estratégias. Ao variá-las, segundo Masetto (2003), pode-se proporcionar o aprendizado aos alunos, atendendo às diferenças individuais que formam uma turma. Para Gil (2012), cabe ao professor colocar o aluno em situações em que se mobilizem com as atividades, possibilitando a manifestação de suas atividades verbais, escritas e 
plásticas. O meio da atividade escolar, de acordo com Gil (2012), não seria o professor e a matéria, mas o aluno ativo e investigador. Ao professor caberia incentivar, orientar e organizar as situações de aprendizagem, adequando-as às capacidades e às características de cada aluno.

Portanto, este artigo propõe-se a investigar as vantagens de ensinar a metodologia da problematização a partir da estratégia World Café com o objetivo de solucionar problemas do cotidiano e contribuir na formação docente. A estratégia foi desenvolvida com alunos de um Programa de PósGraduação em Ensino de uma Universidade do Rio Grande do Sul. Os dados foram recolhidos por meio do diário de bordo dos pesquisadores, filmagem e anotações dos alunos em cartolinas. Destacase que os alunos deste Programa são professores das diversas áreas do conhecimento, desde a Educação Infantil até o Ensino Superior. Aliado a isto, salienta-se que os mesmos buscam, como um de seus objetivos, melhorar a prática pedagógica.

Além desta introdução, a segunda seção refere-se à metodologia da problematização com o Arco de Maguerez, uma das metodologias ativas utilizadas, principalmente, no ensino superior do Brasil que tem duas características principais: o aluno como protagonista principal do seu aprendizado e desenvolvimento e o professor como orientador e mediador metodológico de todo o processo. Posteriormente, é apresentada a estratégia de ensino World Café escolhida para ensinar as cinco etapas do Arco de Maguerez e, dessa forma, o funcionamento prático da metodologia da problematização. A quarta seção analisa os dados de acordo com as cartolinas, filmagens e diário de bordo e discute os principais resultados. Por fim, na última seção, apresenta-se a conclusão do estudo.

\section{METODOLOGIA DA PROBLEMATIZAÇÃO}

A metodologia da problematização tem o objetivo de problematizar a realidade e buscar soluções para os problemas observados, possibilitando o desenvolvimento do raciocínio reflexivo e crítico do aluno. É um caminho metodológico de pesquisa e pode ser utilizada em todas as áreas de conhecimento. A metodologia da problematização está sendo desenvolvida na Universidade Estadual de Londrina, desde 1992, em uma perspectiva de educação transformadora (COLOMBO; BERBEL, 2007). Primeiramente, parte-se da observação da realidade para compreendê-la, problematizá-la com a finalidade de construir conhecimento capaz de solucionar o problema de estudo e transformar a realidade.

Quando existir algo que esteja suscitando a busca de informações e soluções, pode ser utilizada a metodologia da problematização com o esquema de Charles Maguerez, denominado Método do Arco, que sofreu algumas adaptações de conteúdo por Bordenave e Pereira. São cinco etapas do Arco de Maguerez, conforme Fig. 1, no qual os participantes realizam ações que possibilitam o exercício da práxis refletida, informada, consciente e intencionalmente transformadora (BERBEL, 1995): 
FIGURA 1: Etapas do Arco de Maguerez

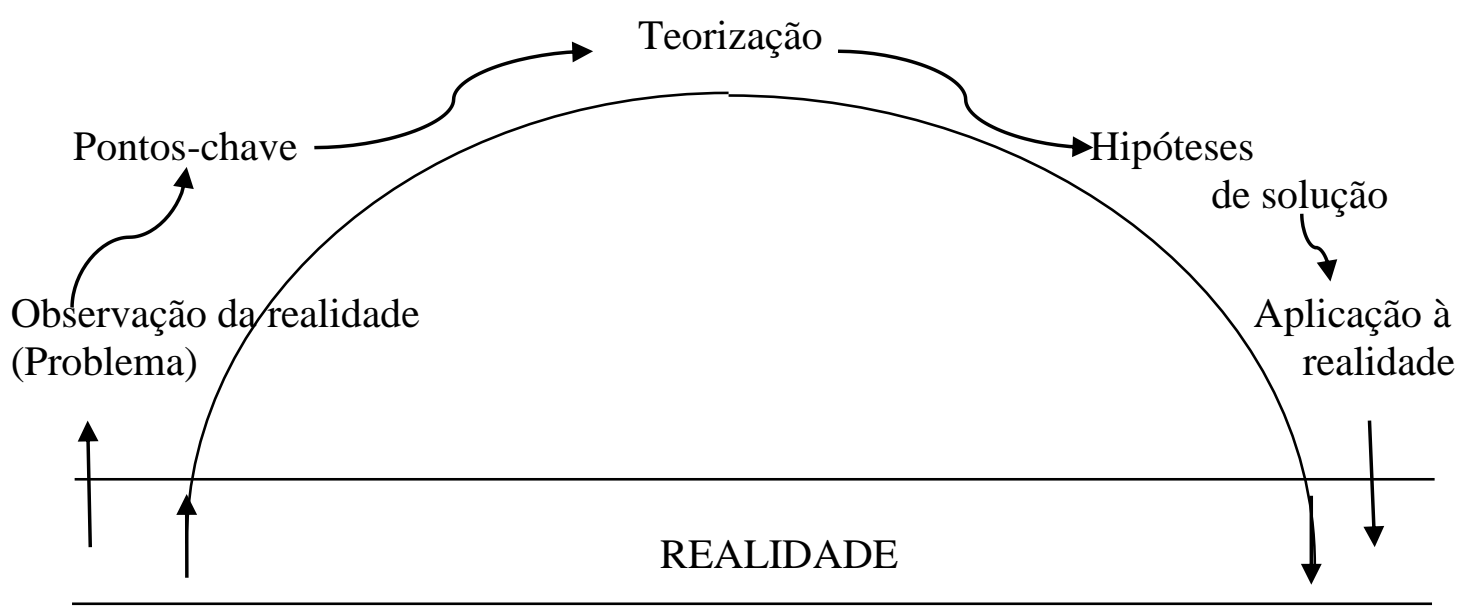

Adaptado por Bordenave e Pereira (1989)

\section{I) Observação da realidade e definição do problema}

A pesquisa começa a partir de um determinado aspecto da realidade. Nessa primeira etapa, os alunos são levados a observar a realidade e identificar problemas com o objetivo de contribuir para a transformação da realidade observada, mediante estudos em grupo. Os alunos, apoiados pelo professor, selecionam uma das situações e a problematizam. Bordenave afirma que "o aluno usa a realidade para aprender com ela, ao mesmo tempo em que se prepara para transformá-la" (BORDENAVE; PEREIRA, 1989, p. 25).

Para estimular os estudantes, os conhecimentos prévios são considerados para dar continuidade ao processo de aprendizagem, através de situações-problema. Um ou mais problemas são escolhidos para estudo e investigação em pequenos grupos. O professor é o animador da discussão enquanto que "o aluno precisa articular os conhecimentos que possui com aqueles que se depara da realidade e formular um problema a partir dos fatos observados que lhe pareçam instigantes" (VILLARDI; CYRINO; BERBEL, 2015, p. 46).

Nesta etapa, os alunos em pequenos grupos observam e decidem qual o problema que irão estudar e solucionar de acordo com o que foi percebido na realidade. Definido o problema a estudar, inicia-se em etapa posterior do Arco de Maguerez (Pontos-Chave), uma reflexão acerca dos possíveis fatores e determinantes maiores relacionados ao problema, possibilitando uma maior compreensão da sua complexidade.

\section{II) Pontos-chave}

Neste momento, os alunos refletirão a respeito das possíveis causas da existência do problema em estudo, quais são os seus determinantes e que variáveis interferem na sua existência. Tal estudo, segundo Rocha (2008, p. 8), "deve ser crítico e reflexivo, tendo em vista que os alunos estão em busca da solução do problema". 
Os alunos, nesta etapa, deverão elaborar uma síntese dos pontos essenciais que deverão ser estudados, com o objetivo de compreender o problema de maneira profunda e encontrar formas de interferir na realidade para solucioná-lo. Berbel (1998) ressalta que os alunos são levados a refletir sobre as possíveis causas da existência do problema. Por que será que o problema existe? De acordo com Villardi et al (2015, p. 47) "este é o momento do aluno definir o aspecto do problema que será objeto de pesquisa. Inicia com uma reflexão, um questionamento sobre os possíveis fatores associados ao problema e que afetam a sua existência".

Em vista disso, os alunos podem pensar em perguntas a responder, tópicos a estudar, aspectos políticos, econômicos, sociais, ambientais e/ou éticos que seriam essenciais para compreensão do problema para resolvê-lo na quinta etapa (aplicação da realidade).

\section{III) Teorização}

É a etapa investigativa, "investigação propriamente dita em que todos os fatos ocorridos e observados são registrados pelo próprios alunos" (GARCIA et al, 2000, p. 3). Os alunos buscam conhecimentos e informações acerca do problema em variadas fontes, usando diferentes maneiras de coletar informações (pesquisa bibliográfica, leituras, entrevistas, consultas a especialistas, pesquisa de campo, etc.).

Os alunos devem organizar, analisar e avaliar as informações obtidas e o quanto podem contribuir para chegar a uma resolução do problema. Na teorização, os alunos adquirem maior consciência do problema e de sua influência sobre o meio social.

Através de discussão e análise, os alunos devem relacionar a teoria com a prática, além de registrar todas as informações para construção de respostas mais elaboradas a respeito do problema. "O registro dessa etapa e das conclusões dela extraídas é necessário para o desenvolvimento da etapa seguinte" (VIEIRA et al, 2015, p. 244). Cabe lembrar que todo o estudo realizado deve servir de base para transformar a realidade.

\section{IV) Hipóteses de solução (alternativas/possibilidades de solução)}

As hipóteses são construídas após o estudo que se obteve na etapa anterior (teorização). As hipóteses são as providências, alternativas e possibilidades de solução para o problema evidenciado inicialmente. Assim, de acordo com Berbel (1998, p. 144):

"Todo o estudo realizado deverá fornecer elementos para os alunos, criativamente, elaborarem as possíveis soluções. $\mathrm{O}$ que precisa acontecer para o problema ser solucionado? O que precisa ser providenciado? O que pode realmente ser feito?".

Portanto, esta é a fase em que o aluno se questiona sobre o que é preciso fazer para solucionar o problema. Diante de todo o estudo, são registradas as alternativas de solução que podem resolvê-lo. A criatividade e a originalidade devem ser bastante estimuladas para se pensar nas alternativas de solução. 


\section{V) Aplicação à realidade}

Nesta etapa devem ser analisadas e escolhidas as hipóteses de solução mais viáveis, que poderão ser colocadas em prática efetivamente. É na quinta etapa que ocorrem os momentos do planejamento e execução das alternativas de solução do problema escolhido.

"Os alunos retornam ao ponto de partida, que é a realidade social e precisam tomar decisões e executá-las, indo além do exercício intelectual, pois assumiram compromisso com a transformação do meio, mesmo que em pequena dimensão" (VIEIRA et al, 2015, p. 244). O aluno é o protagonista, responsável pelo seu aprendizado e atuação no meio em que vive.

Nesse sentido, o problema deve ser solucionado na sua totalidade ou parcialmente, contribuindo para a transformação da realidade inicial. Segundo Rocha (2008, p. 9), "fecha-se, dessa maneira o Arco de Maguerez, com o intuito de levar os alunos a uma prática de ação-reflexão-ação, ou seja, aprenderem o conteúdo de maneira crítica e reflexiva, partindo de sua própria realidade social”.

Por fim, nesta etapa o aluno retorna à realidade inicial, põe em prática no meio social aquilo que foi observado, discutido, questionado, refletido e teorizado para aplicar a solução do problema.

\section{ESTRATÉGIA WORLDCAFÉ}

O World Café possibilita maior interação e envolvimento da turma, desenvolvendo nos alunos a criatividade e o espírito colaborativo. O grande diferencial desta estratégia é a movimentação que acontece nos pequenos grupos, tornando possível o compartilhamento do conhecimento, a aprendizagem colaborativa e o desenvolvimento da inteligência coletiva. Sem dúvida, é eficiente e inovadora em sala de aula, despertando o interesse dos alunos pela pesquisa e pelo prazer em aprender. Conforme Brown e Isaacs (2008), apud Machado e Passos (2017, p. 836):

O World Café é uma técnica que vem sendo utilizada em vários países com o objetivo de potencializar diálogos e viabilizar a construção coletiva de proposições em torno de temas relevantes nos diversos campos de conhecimento. Visa ao estabelecimento de um espaço dialógico que, por meio de perguntas, estimula a participação das pessoas na emissão de opiniões e construção coletiva de entendimento sobre um objeto que é apresentado como cerne para a discussão.

De acordo com o documento produzido pelo The World Café Community (2015), para a realização do World café é necessário dividir a turma em grupos de aproximadamente quatro alunos para a discussão e compreensão de temas/problemas que sejam importantes para os participantes. Cada grupo ficará em uma mesa para discutir o tema escolhido pelo responsável/professor e/ou plenário ou para discutir o tema/problema escolhido pelo seu próprio grupo. Após completar o tempo estipulado para o diálogo inicial, acontece o primeiro movimento entre os grupos.

A propósito, destacam Machado et al., 2017, p. 836:

Um dos diferenciais do world café consiste em garantir a agilidade e fluidez entre os grupos, de modo a permitir que os participantes transitem por diversos arranjos grupais e não permaneçam com as mesmas pessoas até o final da atividade. O que é mais relevante é que haja a circulação das ideias por parte de quem segue para os demais grupos (nos diferentes temas) e a preservação do que já fora discutido para que seja utilizado como insumo entre os demais que aterrissam naquele determinado ponto a ser discutido. 
Geralmente, acontecem três rodadas nas quais os participantes, exceto o relator, atuam como viajantes, levando ideias, contribuições para outras mesas em um curto espaço de tempo. É escolhido um anfitrião/relator, que tem a função de registrar a discussão realizada no seu grupo e dos demais participantes que passarem pela sua mesa durante as rodadas. Cabe ao anfitrião, também, manter-se na mesa até o final da atividade, para depois socializar para o grande grupo toda a discussão realizada sobre o tema/problema.

Segundo Brown \& Isaacs (2008), o cerne do trabalho com o World Café está na participação ativa dos membros dos grupos e tem como consequência a construção de uma inteligência coletiva a respeito do tema elencado para o debate. Logo, ao longo da sua realização, estimular a fala e a exposição das ideias e dos contrapontos entre os participantes é uma tarefa importante e que merecerá a atenção de quem está conduzindo o processo.

Sendo assim, é importante que o responsável/professor atue como mediador/incentivador. Cabe destacar, também, que podem acontecer diversas rodadas nas quais os participantes escutam, refletem, contribuem e saboreiam um belo café com outras bebidas, doces e salgados. Na última rodada de diálogo, os participantes retornam a sua mesa/grupo inicial para aprofundar o seu conhecimento diante dos movimentos realizados e contribuições dos colegas apontadas pelo anfitrião. Existem casos em que é permitido, no final, que o anfitrião se movimente, cabendo ao grupo escolher um novo relator.

Por fim, concluídas todas as rodadas, o anfitrião/relator socializa com os membros do seu grupo as contribuições registradas dos demais participantes. Posteriormente, o anfitrião apresenta para a turma (grande grupo) a produção final, podendo, ainda, ter a contribuição dos demais componentes da turma, caso alguma situação não tenha sido discutida. O professor/responsável media a discussão e, ao final, caso haja necessidade, o professor complementa as ideias apresentadas.

\section{ANÁLISE E RESULTADOS}

Com o intuito de identificar as limitações e potencialidades da metodologia da problematização a partir da estratégia World Café, foi desenvolvida uma experiência com uma turma de Doutorado em Ensino, de uma Universidade no estado do Rio Grande do Sul, por um período de duas semanas, para contribuir na formação desses profissionais.

Cabe ressaltar que o objetivo principal do referido Programa de Pós-Graduação é proporcionar qualificação da formação docente para atuação no sistema educacional em todos os níveis de ensino. Nessa ótica, pensar em formação docente implica necessariamente problematizar, redimensionar e reconstruir os processos de ensino e aprendizagem, acarretando impacto no campo científico, tecnológico e social de um país, o que justifica o estudo teórico e prático da metodologia da problematização para contribuir na formação e prática pedagógica dos professores da educação básica e do ensino superior.

Nesse contexto, a turma foi orientada, pelos pesquisadores, no primeiro dia de aula a observar durante uma semana problemas do cotidiano que gostariam que fossem discutidos em sala de aula. Os registros poderiam ser realizados a partir de fotos, filmagens, desenhos, escritas, etc. 
Na semana seguinte, segunda aula, foi explicado pelos pesquisadores o que é a metodologia da problematização, em que áreas de conhecimento vêm sendo aplicada, quais as cinco etapas do Arco de Maguerez e que o objetivo da aula era aprender as etapas da metodologia da problematização a partir da estratégia World Café para contribuir na formação e prática pedagógica. Cabe destacar que os alunos, apesar de serem de áreas de conhecimento diversas, são professores da educação básica e/ou ensino superior. Na sequência, também, foi explicado, pelos pesquisadores, o funcionamento do World Café.

Antes de iniciar a atividade, os alunos tiveram que escolher e estourar um balão de aniversário da cor de sua preferência para saber o presente (doce) que teriam recebido e formar um grupo com colegas que tivessem sido presenteados com o mesmo doce. Cabe ressaltar que durante toda a atividade, os alunos podiam se dirigir à mesa de alimentação para buscar bebida, doce e/ou salgado de sua preferência.

Sendo assim, a turma foi dividida em três grupos e foi solicitado que escolhessem um problema evidenciado na semana anterior para ser estudado. Os três problemas escolhidos e estudados em sala de aula foram: 1) dificuldade dos alunos em fazer pesquisa; 2) separação e reciclagem do lixo; e 3) descarte de lixo em local indevido. Questionados pelos pesquisadores por que escolheram esses temas, os pós-graduandos disseram que são problemas que estão presentes em muitas escolas e universidades e precisam ser solucionados. Como professores da educação básica e/ou ensino superior, independentemente da área de conhecimento, é necessário discutir e ensinar os alunos a fazer pesquisa, separar o lixo e não jogá-lo em local indevido.

Cada grupo recebeu cartolinas coloridas, canetinhas, tinta, pincel, tablets com acesso a internet, livros, revistas, jornais, etc. para o desenvolvimento das atividades. Em um intervalo de duas horas, os alunos estudaram, pesquisaram e registraram nas cartolinas de maneira sintetizada as cinco etapas do Arco de Maguerez a partir do problema escolhido. As produções nas cartolinas dos três grupos estão nas Figuras 2, 3 e 4 : 
FIGURA 2: Dificuldade dos alunos em fazer pesquisa

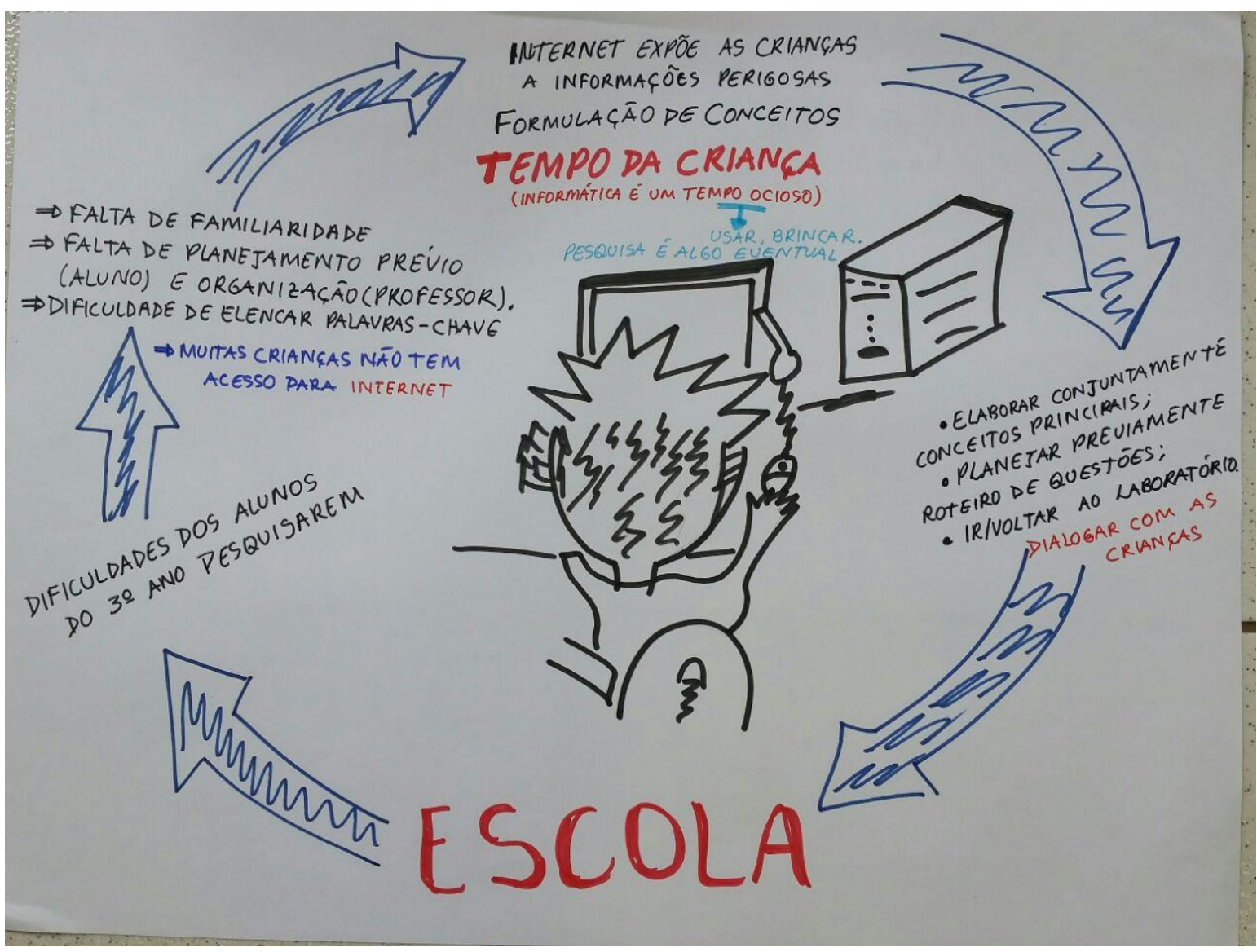

Fonte: Grupo 1 - Alunos.

A dificuldade dos alunos em fazer pesquisa no computador e se concentrar, conforme registrado na Fig. 2, é um problema pedagógico. Foram consultados artigos científicos e reportagens para entender o problema e refletir sobre as possibilidades de solução, tais como:

1) A importância da pesquisa na escola (Revista Exame. Disponível em:

https://educador.brasilescola.uol.com.br/orientacoes/a-importancia-pesquisa-na-escola.htm);

2) Uma classificação sobre a utilização do computador pela escola (Revista Educação em Debate.

Disponível em: http://www.periodicosfaced.ufc.br/index.php/educacaoemdebate/article/view/355);

3) A informática e as dificuldades de aprendizagem: repensando o olhar e a prática do professor no cotidiano da sala de aula. (Disponível em:

https://www.researchgate.net/publication/228737519_A_informatica_e_as_dificuldades_de_aprendizage m_repensando_o_olhar_ea_pratica_do_professor_no_cotidiano_da_sala_de_aula?enrichld=rgreqe3ceaf 252badad6d455d834e983d2bafXXX\&enrichSource=Y292ZXJQYWdlOzlyODczNzUxOTtBUzo5OTUwM DYyNjU0NjY5OUAxNDAwNzMOMjA2NTIx\&el=1_x_2\&_esc=publicationCoverPdf);

4) As crianças como pesquisadoras: os efeitos dos direitos de participação sobre a metodologia de pesquisa (Red de Revistas Científicas de América Latina y el Caribe, España y Portugal. Disponível em: http://www.redalyc.org/html/873/87313716007/). 
Por fim, como possibilidades de solução (4 ${ }^{\circ}$ etapa do Arco de Maguerez), o professor deve, inicialmente, fazer um planejamento do que pretende ensinar no laboratório de informática, refletir sobre a melhor forma de executar a sua proposta e de incentivar seus alunos a fazerem pesquisa, orientando-os, atuando como mediador, permitindo um certo grau de dispersão, quando se tratar de alunos dos anos iniciais. Cabe ao professor discutir o tema escolhido antes de levá-los para o laboratório, para que quando os alunos fiquem diante do computador saibam o que pesquisar. Ensinar como se faz pesquisa, quais são as fontes confiáveis, como selecionar informação são tarefas do professor.

FIGURA 3: Separação e reciclagem do lixo

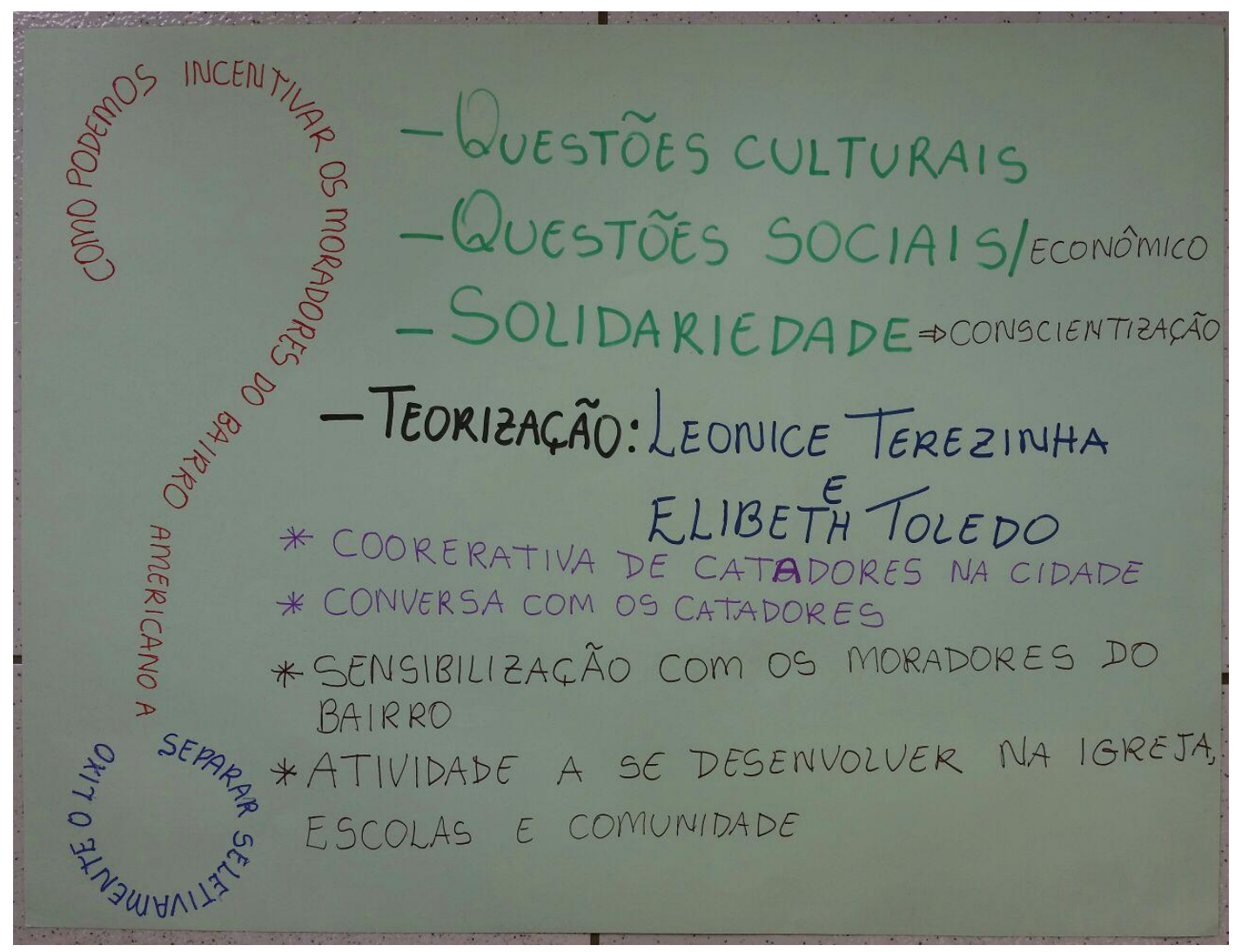

Fonte: Grupo 2 - Alunos.

Conforme o grupo destaca na Fig. 3, parece existir uma certa dificuldade das pessoas compreenderem a importância da separação e reciclagem do lixo. Não existe cuidado na separação de garrafas plástica e vidro, nem separação de embalagens de papelão ou metal. Percebe-se, também, que algumas pessoas visitam a lixeira, para coletar o lixo que os moradores não separam. Como fontes de pesquisa foram consultados na etapa da teorização do Arco de Maguerez:

1) A importância da conscientização e da coleta seletiva no município de Palmitos (Disponível em http://repositorio.roca.utfpr.edu.br/jspui/handle/1/4537); 
2) Proposta de implementação da coleta seletiva de lixo (com o aproveitamento de garrafas pets e latas de alumínio) no condomínio residencial prive das laranjeiras em Goiânia (Disponível em http://www.agu.gov.br/page/download/index/id/19461321);

3) Reciclagem (Disponível em: http://mundoeducacao.bol.uol.com.br/geografia/reciclagem.htm);

4) Reciclagem (Disponível em: https://www.suapesquisa.com/reciclagem/);

5) Reciclagem de lixo em uma escola pública de Salvado (Disponível em:

http://www.gepexsul.unisul.br/extensao/2012/amb3.pdf).

Diante do estudo realizado, o grupo acredita que um dos aspectos importantes para o problema da separação e reciclagem do lixo é que se trata de uma questão cultural. As pessoas, ao produzirem o seu lixo, em casa, no trabalho, local de estudo, querem se livrar rapidamente. Se não existir consciência de que é preciso separar o lixo para reciclagem, ele vai retornar, poluindo a água, o ar, o planeta. As hipóteses de solução seriam a coleta seletiva do lixo, organização nos horários de coleta, propagandas que destacassem a importância de separar o lixo, atividades educativas em escolas e universidades para despertar a consciência ambiental, incentivos e benefícios como redução de impostos para as propriedades que separam o lixo.

FIGURA 4: Descarte de lixo em local indevido

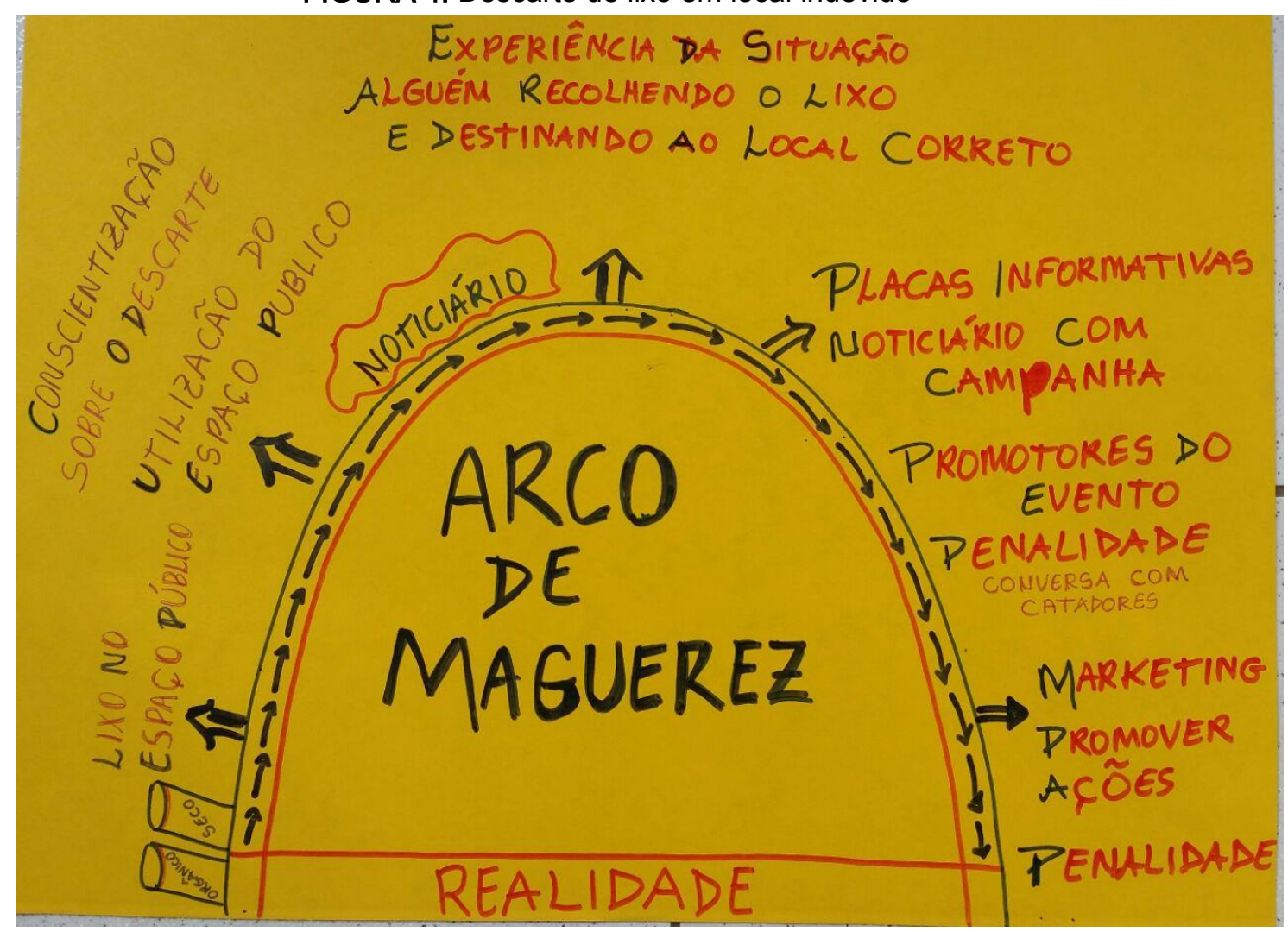

Fonte: Grupo 3 - Alunos.

Como se pode perceber, os problemas evidenciados no cotidiano pelos alunos dos grupos 2 e 3 têm algo em comum, são ocasionados por questões culturais, falta de conscientização e 
comprometimento. O problema destacado na Fig. 4 refere-se a uma situação em que torcedores de um time de futebol saíram do estádio para comemorar o título em outro local público no qual existiam lixeiras e os torcedores, por algum motivo sem explicação lógica, resolveram jogar as latas de cerveja e refrigerante no chão ou ao lado da própria lixeira. Não existiu uma conscientização dos torcedores em jogar o lixo no lugar correto naquele dia. O problema ganhou destaque em telejornais da região e internet:

1) Limpeza na Avenida Goethe. (Rede Globo. Disponível em: https://g1.globo.com/rs/rio-grande-dosul/noticia/limpeza-na-avenida-goethe-aos-festa-de-torcedores-do-gremio-gera-bloqueio-parcial.ghtml); 2) Festa do tri deixa pelo menos 20 toneladas de lixo na Goethe. (Rádio Gaúcha. Disponível em: https://gauchazh.clicrbs.com.br/porto-alegre/noticia/2017/11/festa-do-tri-deixa-pelo-menos-20toneladas-de-lixo-na-goethe-cjamw2ahl00bd01mkcs54ojvd.html);

3) Final da Libertadores geral acúmulo de 16 toneladas de lixo (Jornal Correio do Povo. Disponível em: http://www.correiodopovo.com.br/Noticias/Geral/2017/11/635438/Final-da-Libertadores-gera-acumulode-16-toneladas-de-lixo);

4) Lixo e impactos ambientais perceptíveis no ecossistema urbano (Revista Sociedade e Natureza.

Disponível em: http://www.scielo.br/pdf/sn/v20n1/a08v20n1).

O problema existe na visão do grupo por falta de educação, respeito e comprometimento por parte de cada um, porque provavelmente as pessoas que estavam sujando o espaço sabiam que no outro dia pela manhã as equipes de limpeza estariam recolhendo todo o lixo, além dos catadores, então não importava se existia lixeira no local. Foi um ato de desrespeito e descomprometimento por parte daquelas pessoas com o espaço público. É preciso cuidar não só do nosso espaço, da nossa casa, mas também daqueles do nosso emprego, de estudo e das ruas por onde caminhamos. Por isso, a educação ambiental seria uma das possibilidades de solução para o problema conforme, também, aborda o artigo selecionado na etapa da teorização: A educação ambiental nos currículos (Revista de Biologia e Ciências da Terra. Disponível em: http://www.redalyc.org/html/500/50010202/).

$\mathrm{Na}$ sequência, foram realizadas três rodadas de quinze minutos cada uma, os professores cronometraram o tempo e avisaram o momento da troca. Esta quantidade de rodadas também pode ser adaptada pelo professor, dependendo da quantidade de grupos. Os alunos trocaram de grupo, movimentando-se em sentido horário, com o intuito de contribuírem com a produção dos demais. Salienta-se que um componente de cada grupo denominado anfitrião/relator permaneceu no seu grupo até o final da estratégia, com a função de relatar aos colegas que estivessem "chegando" o que foi discutido até aquele momento.

Concluídas as rodadas, os alunos retornam para o grupo inicial. Neste momento, cada anfitrião/relator socializou com o seu grupo as contribuições realizadas pelos demais colegas nas cartolinas. Posteriormente, os três anfitriões apresentaram para a turma a produção final. Os pesquisadores/autores deste estudo mediaram a discussão e ao final complementaram as ideias apresentadas. 
Para finalizar, os pesquisadores disponibilizaram um tempo para que os alunos falassem sobre suas percepções em relação ao aprendizado da metodologia da problematização a partir da estratégia World Café, ressaltando pontos positivos e/ou negativos.

Os dados coletados para análise foram obtidos por meio dos depoimentos dos participantes. Registros de percepções dos pesquisadores e condutores da atividade também constituem dados de análise juntamente com os materiais produzidos pelos alunos.

A dinamização da aula, a integração e a socialização proporcionada pela estratégia foram apontadas pelos alunos como aspectos positivos, conforme se pode observar nos comentários feitos no final da atividade:

\begin{abstract}
A estratégia world café permitiu que os grupos circulassem e contribuíssem com os mais variados aspectos. A aula foi muito produtiva, tivemos a oportunidade de escutar os colegas, como eles pensam, não só como a gente pensa. A questão de andar pela sala e fazer rodízio nos grupos foi muito interessante, os colegas sempre tinham algo a acrescentar e foi possivel refletir sobre coisas que não teríamos refletido sozinhos ou nos pequenos grupos, porque cada pessoa tem o seu entendimento (A1).

A estratégia world café possibilitou a discussão no grupo, a troca de ideias, a troca de experiências, que cada um trouxe para aquele momento. Então houve, eu vejo assim, como importantíssimo, exatamente, essa troca de conhecimento que foi vivenciado ali durante a aplicação da estratégia (A2).

World Café é muito interessante, porque vai descontraindo, ao mesmo tempo vai trazendo os colegas e eles vão participando no momento que vão fazendo os rodízios, eles vão vindo e vão olhando, com aquele outro olhar e dizem: "mas tu pensaste dessa forma, quem sabe poderia ser assim". E isso que é o bacana (A3).

A aula ficou mais agradável com a utilização da estratégia, por possibilitar a participação de todos, é assim que se aprende (A4).

Eu gostei bastante, sou uma pessoa que gosta de movimento, eu gosto de ser desafiada, de ter interação com os colegas, de fazer atividades diferentes. Eu acho que essa estratégia foi bem rica para as discussões da metodologia da problematização e para o cumprimento das cinco etapas do Arco de Maguerez. Não tem como sair de uma aula dessas sem aprender (A5).
\end{abstract}

Diante dos depoimentos dos alunos, reconfigurar o formato com que as aulas são desenvolvidas é um desafio aos professores dos diferentes níveis de ensino, visto que o novo contexto social não tem mais espaço para que o professor assuma o papel de detentor do conhecimento e passe horas discursando, enquanto o aluno permanece na condição de mero receptor. Contudo, cabe ressaltar a importância do planejamento para ensinar determinado conteúdo a partir de uma metodologia ativa, pois desta forma será possível conduzir as discussões e gerenciar com segurança possíveis conflitos oriundos das discussões. Alberti et al (2014) afirmam que o planejamento deve contemplar a intenção, organização e sistematização, priorizando espaços para que os alunos expressem-se socialmente e dialoguem com o grupo, socializando ideias e administrando os conflitos inerentes às atividades em grupo. 


\section{CONCLUSÃO}

Para Freire (1980), o professor deve desenvolver uma postura dialógica em suas aulas, promovendo debates em que o aluno possa tomar parte com suas próprias ideias. Segundo Anastasíou (2003), é preciso compreender que a aula, iniciando de forma expositiva e dialogada, pode caracterizar um avanço no ensino tradicional. Tradicionalmente, o aluno vai para a aula esperando assistir à exposição do conteúdo pelo professor. Em uma exposição dialogada, ocorre um processo de parceria entre professor e aluno.

Nesse sentido, cabe destacar que foi possível compreender as vantagens de ensinar a metodologia da problematização com o Arco de Maguerez a partir da estratégia World Café com o objetivo de solucionar problemas do cotidiano e contribuir na formação docente. $\mathrm{O}$ intuito foi explorar a possibilidade de que, a partir de tais estratégias, o aluno assuma o papel de protagonista, pesquisando nos livros, revistas, jornais, tablets fornecidos, expondo suas próprias ideias sobre o problema, interagindo com os colegas, analisando, refletindo, questionando, levantando hipóteses e compartilhando ideias. Portanto, acredita-se que a experiência realizada contribuiu na formação e prática pedagógica dos doutorandos e tem potencial para ser desenvolvida com os alunos desde a Educação Infantil até o Ensino Superior, com as devidas adaptações.

Os três problemas abordados pelos grupos foram: dificuldade de os alunos fazerem pesquisa no computador, seleção/reciclagem do lixo e descarte de lixo em local indevido. Como possíveis soluções para o primeiro problema, foram destacados: o planejamento do professor do que pretende ensinar no laboratório de informática, a reflexão sobre a melhor forma de executar a sua proposta e incentivar seus alunos a fazerem pesquisa, orientando-os na busca de informações. Com relação ao problema da seleção e reciclagem do lixo, foram apontadas como hipóteses de solução: a coleta seletiva do lixo em horários diferenciados, a divulgação da importância de selecionar o lixo, promoção de atividades educativas em escolas e universidades para despertar a consciência ambiental e incentivos como redução de impostos, etc. A educação ambiental seria uma das possibilidades de solução para o problema de descarte do lixo em local indevido.

Ao analisar os comentários dos alunos no final da aula, constatou-se que as atividades propostas apresentaram pontos positivos, uma vez que possibilitaram maior compreensão do problema e da metodologia (etapas do Arco de Maguerez), estreitamento da teoria com a prática e interação da turma, tornando a aula mais atrativa e envolvente com a utilização da estratégia World Café. Percebeuse que os alunos ficaram estimulados e motivados a usar estas estratégias em sua prática pedagógica.

Nesse contexto, durante a aprendizagem, é interessante usar múltiplas estratégias. Ao variá-las, segundo Masetto (2003), pode-se proporcionar o aprendizado aos alunos, atendendo às diferenças individuais que formam uma turma. Para Gil (2012), cabe ao professor colocar o aluno em situações em que se mobilize com as atividades, possibilitando a manifestação de suas atividades verbais, escritas e plásticas. O meio da atividade escolar, de acordo com Gil (2012), não seriam o professor e a matéria, mas o aluno ativo e investigador. Ao professor caberia incentivar, orientar e organizar as situações de aprendizagem, adequando-as às capacidades e às características de cada aluno. 


\section{REFERÊNCIAS}

1. ALBERTI, T. F.; ABEGG, I.; COSTA, M. R. J.; TITTON, M. Dinâmicas de grupo orientadas pelas atividades de estudo: desenvolvimento de habilidades e competências na educação profissional. Revista Brasileira de Estudos Pedagógicos (online). Brasília, v. 95, n. 240, p. 346-362, 2014.

2. ANAStASíOU, L. das G. C. e ALVES, L. P. Processos de ensínagem na universidade: pressupostos para as estratégias de trabalho em aula. 5ed. Joenville, SC: Unlville, 2003.

3. BERBEL, N. A. N. Metodologia da problematização: uma alternativa metodológica apropriada para o ensino superior. Revista Semina: Ciências Sociais e Humanas. Londrina, v. 16, n. 2, p. 9-19, 1995.

4. BERBEL, N. A. N. A problematização e a aprendizagem baseada em problemas: diferentes termos ou diferentes caminhos? Revista Interface - Comunicação, Saúde e Educação. São Paulo, v. 2, p. 139-154, 1998.

5. BORDENAVE, J. D.; PEREIRA, A. M. Estratégias de ensino aprendizagem. 4. ed. Petrópolis: Vozes, 1989.

6. BROWN, J.; ISAACS, D. The World Café: Awakening Collective Intelligence and Committed Action. In: M. Torvey Collective Intelligence: Creating a Prosperous World at Peace. Earth Intelligence Network. Virginia, 2008.

7. COLOMBO, A. A.; BERBEL, N. A. N. A metodologia da problematização com o Arco de Maguerez e sua relação com os saberes de professores. Revista Semina: Ciências Sociais e Humanas. Londrina, v. 28, n. 2, p. 121-146, 2007.

8. FREIRE, P. Educação como prática da liberdade. São Paulo: Paz e Terra, 1980.

9. GARCIA, M. F. L. G; LORENCINI JR, A.; ZÔMPERO, A. F. Análise da metodologia da problematização utilizando temas da sexualidade: tendências e possibilidades. Anais VII Encontro Nacional de Pesquisa em Educação em Ciências. Florianópolis, 2000.

10. GIL, A. C. O que é didática no ensino superior. São Paulo: Atlas, 2012.

11. MACHADO, M. P. M.; PASSOS, M. F. D. O uso do world café como método de pesquisa junto às equipes de saúde. Atas 6 Congresso Ibero-Americano de Investigação Qualitativa. Salamanca, $\begin{array}{llllll}\text { Espanha, } & \text { v. } & 2, & \text { p. } & \text { 835-840, } & \text { Disponível }\end{array}$ 
<http://proceedings.ciaiq.org/index.php/ciaiq2017/article/viewFile/1280/1240>. Acesso em: 07/01/2018.

MASETTO, M. T. Competência pedagógica do professor universitário. São Paulo: Summus, 2003.

NÓVOA, A. Para uma formação de professores construída dentro da profissão. In: Professores: imagens do futuro presente. Lisboa: Educa, 2009.

14. ROCHA, R. O método da problematização: prevenção às drogas na escola e o combate a violência. Programa de Desenvolvimento Educacional da Secretaria de Estado da Educação. Universidade Estadual de Londrina, Paraná, 2008.

SANTOS, W. L. P. dos. Educação científica na perspectiva de letramento como prática social: funções, princípios e desafios. Revista Brasileira de Educação. Rio de Janeiro, v. 12, n. 36, 2007.

16. THE WORLD CAFÉ COMMUNITY. Café to go! $A$ quick reference guide for hosting world café. 2015. Disponível em http://www.theworldcafe.com/wp-content/uploads/2015/07/Cafe-To-GoRevised.pdf.Acesso em: 20 de fevereiro de 2018.

17. VIEIRA, M. N. C. M.; PINTO, M. P. P. A metodologia da problematização (MP) como estratégia de integração ensino-serviço em cursos de graduação na área da saúde. Revista da Faculdade de Medicina de Ribeirão Preto. USP, São Paulo, v. 48, n. 3, p. 241-248, 2015.

18. VILLARDI, M. L.; CYRINO, E. G.; BERBEL, N. A. N. A metodologia da problematização no ensino em saúde: suas etapas e possibilidades. In: A problematização em educação em saúde: percepções dos professores tutores e alunos (online). São Paulo: UNESP, 2015.

19. WERNER, D.; BOWER, B. Aprendendo e ensinando a cuidar da saúde. 3. ed. São Paulo: Paulinas, 1984.

\section{Patricia da Graça Rocha Franzoni}

Graduada em Ciências Econômicas (FURG), Mestra em Economia (UFPB/João Pessoa), Professora Adjunta III (Economia/FURG), Discente no Programa de Pós-Graduação - Doutorado em Ensino (UNIVATES) e Bolsista da Coordenação de Aperfeiçoamento de Pessoal em Nível Superior (CAPES).

\section{Romildo Pereira Cruz}

Graduado em Matemática (UFAM), Especialista em Ensino de Matemática (UFAM), Mestre em Ensino (UNIVATES), Professor Auxiliar (UEA), Discente no Programa de Pós-Graduação - Doutorado em Ensino (UNIVATES) e Bolsista da Coordenação de Aperfeiçoamento de Pessoal em Nível Superior (CAPES). 


\section{Marli Teresinha Quartieri}

Graduada em Matemática e Ciências (FECLAT), Especialista em Educação Matemática (UNISC), Mestrado em Matemática (UFRGS), Doutora em Educação (UNISINOS), Professora da Graduação e Pós-Graduação (Mestrado e Doutorado em Ensino e Mestrado e Doutorado em Ensino de Ciências Exatas - UNIVATES), Bolsista de Produtividade de Pesquisa (CNPq - Nível 2).

Como citar este documento:

FRANZONI, Patricia da Graça Rocha; CRUZ, Romildo Pereira; QUARTIERI, Marli Teresinha. Ensinando a metodologia da problematização com o Arco de Maguerez a partir da estratégia World Café. Reflexão e Ação, Santa Cruz do Sul, v. 27, n. 3, p. 191-207, out. 2019. ISSN 1982-9949. Disponível em: <https://online.unisc.br/seer/index.php/reflex/article/view/12191>. Acesso em: doi:https://doi.org/10.17058/rea.v27i3.12191. 